\title{
Analisis Karakteristik Pembangkit Listrik Hot Air Stirling Engine Dengan Bahan Bakar Metanol
}

\author{
Noorly Evalina, Basuendro Putro, Zulfikar \\ Program Studi Teknik Elektro, Fakultas Teknik \\ Universitas Muhammadiyah Sumatera Utara (UMSU) \\ Jl. Kapten Muchtar Basri,BA No. 03 Medan Telp. (061) 6622400 ex. 12 Kode pos 20238 \\ e-mail: noorlyevalina@umsu.ac.id
}

\begin{abstract}
Abstrak - Mesin stirling merupakan suatu mesin kalor yang digerakkan melalui siklus kompresi dan ekspansi pada fluida kerja dalam wujud gas. Pada prinsip kerjanya ada 3 tipe mesin stirling yaitu tipe Alpha, Beta dan tipe Gamma. Secara Umum Skema Kerja Mesin ini, pada suhu yang berbeda fluida kerja terjadi perbedaan tekanan yang dapat menimbulkan perubahan energi panas menjadi energi kerja mekanik yang akan menggerakkan roda flywheel yang dihubungkan dengan generator DC sehingga dapat menimbulkan energi listrik. Bahan yang digunakan adalah Metanol yang dapat diperbaharui sehingga dapat menghemat bahan bakar fosil yang masih tersedia.Listrik yang dihasilkan kemudian dapat digunakan setelah melalui joule thief inverter dan dapat diterima pada lampu 3 watt AC, bahwa saat berbeban kecepatan putaran yang dihasilkan jauh lebih kecil dimana pada saat tanpa beban pada waktu 20 detik putaran yang dihasilkan $491 \mathrm{rpm}$, sedangkan saat berbeban kecepatan putaran yang dihasilkan 334 rpm
\end{abstract}

Kata kunci : Striling Engine, Methanol, Joule Thief Inverter

Abstract - Stirling engine is a heat engine that is driven through a cycle of compression and expansion of the working fluid in the form of gas. In principle, there are 3 types of stirling engines, namely Alpha, Beta and Gamma types. In general, the Machine Work Scheme, at different temperatures the working fluid occurs a difference in pressure that can cause changes in heat energy into mechanical work energy that will drive the flywheel wheel which is connected to a DC generator so as to cause electrical energy. The material used is renewable Methanol so that it can save fossil fuels that are still available. The electricity produced can then be used after going through a joule thief inverter and can be received on a 3 watt AC lamp, that when loaded the rotation speed produced is much smaller where at when no load at 20 seconds the rotation generated $491 \mathrm{rpm}$, while when the resulting rotation speed is $334 \mathrm{rpm}$

Keywords : $\quad$ Striling Engine, Methanol, Joule Thief Inverter

\section{PENDAHULUAN}

Seiring dengan kemajuan teknologi saat ini, perangkat listrik pada awalnya membutuhkan energi yang besar, secara bertahap mulai berganti dengan perangkat hemat listrik dan lebih ramah lingkungan. Upaya untuk konservasi (penghematan) listrik kemungkinan besar akan terus berkembang. Ketersediaan energi listrik yang diberikan tidak seimbang dengan kebutuhan seiring dengan pertumbuhan gaya hidup masyarakat pada umunya [1].

Untuk memenuhi kebutuhuhan energi yang terus menigkat, maka perlu dikembangkan berbagai pembangkit listrik seperti hot air stirling engine yang ditemukan oleh Robert Stirling (17901876) pada tahun 1816. Motor stirling adalah jenis motor yang memiliki ciri pembakaran luar (external combustion engine) dan membutuhkan sumber energi termal untuk menggerakkannya atau dengan kata lain multi bahan bakar [2].

Berbagai cara telah dilakukan untuk mencari bahan bakar alternatif sebagai pengganti dari bahan bakar fosil. Dimana diharapkan bahan bakar alternatif tersebut tetap dapat memberikan performa yang baik dan tentunya emisi gas buang yang dihasilkan ramah terhadap lingkungan.Dengan bahan bakar fosil yang semakin lama semakin menipis, bahan bakar spirtus dapat dijadikan sebagai sumber energi baru karena spiritus adalah sumber energi yang dapat diperbaharui [3].

Penelitian ini bertujuan untuk menganalisis sebuah pembangkit listrik dengan menggunakan hot air stirling engine dengan kapasitas 1 Volt DC sampai 3 Volt DC dengan menggunakan rangkaian joule thief inverter untuk dibebani dengan beban listrik AC (bolak - balik). 


\section{TINJAUAN PUSTAKA}

Mesin stirling merupakan mesin dengan jenis pembakaran luar dengan siklus tertutup yang mengubah energi panas menjadi energi gerak dengan menggunakan udara atau gas sebagai fluida kerjanya. Mesin stirling dapat membakar setiap bahan bakar padat atau cairan sebagai sumber pemanasnya. Hal ini menyebabkan mesin stirling sangat menarik, khususnya pada situasi dimana bahan bakar konvensional sangat mahal dan sulit untuk memperolehnya. Pada dasarnya sistem pembangkit listrik dengan generator stirling mempunyai beberapa komponen untuk membangkitkan sebuah beban yang akan menghasilkan tegangan, arus, dan daya. Dalam hal ini pengaruh energy panas menjadi salah satu faktor utama dalam penentuan bentuk dan jenis dari mesin stirling yang akan digunakan agar keluaran daya listrik dan tingkat kestabilan dari putaran pada mesin stirling menjadi maksimal [3].

Hot Air Stirling Engine merupakan salah satu media konversi energi alternative perkembangan motor bakar menuju kearah motor bakar yang ramah lingkungan yang menekankan pada pemakaian biaya yang lebih rendah. Ekspansi gas ketika di panaskan dan di ikuti kompresi gas ketika di dinginkan, bahan bakar sampah plastik digunakan sebagai sumber energi kalor yang dikonversikan oleh Hot Air Stirling Engine menjadi energi mekanik dan kemudian dikonversi menjadi energi listrik, hasil output pengujian mulai bergerak setelah tabung kaca displacer dipanaskan selama 60 detik dan pada $43^{\circ} \mathrm{C}$ diukur pada silinder displacer yang tidak terkena api pembakaran bahan bakar sampah plastik. Pengujian ini dihitung bertahap selama 30 detik setiap pengukuran dan diakhiri dengan waktu 330 detik, pada saat temperatur $43^{\circ} \mathrm{C}$ putaran yang dihasilkan $821 \mathrm{rpm}$, dan setelah temperature $68^{\circ} \mathrm{C}$ putaran yang dihasilkan semakin besar $1466 \mathrm{rpm} \mathrm{[4]}$

\section{Pengertian Stirling Engine}

Stirling Engine adalah mesin kalor yang mengambil kalor dari luar silinder kerjanya. Sumber kalor apapun selama temperaturnya cukup tinggi, akan bisa menggerakan motor ini. Secara prakteknya siklus Stirling Engine berbeda dengan siklus teoritik yang di dalamnya terdapat proses dua temperatur konstan dan dua volume konstan [5].

\section{MESIN STIRLING}

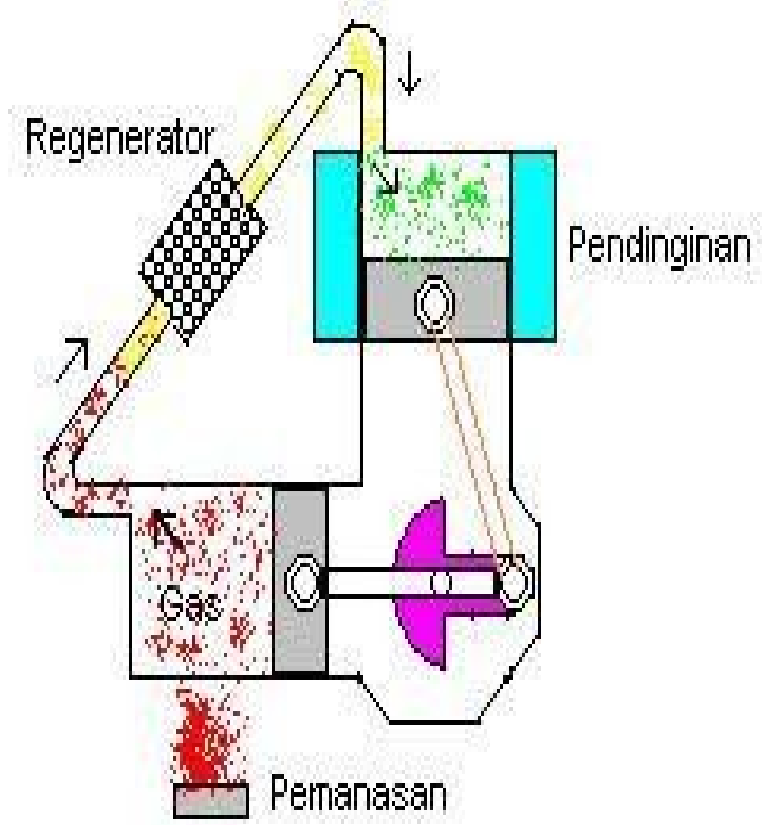

Gambar 1 Sistem pembakaran Stirling Engine

Stirling Engine merupakan mesin pembakaran eksternal yang menggunakan udara atau gas (helium, hydrogen, nitrogen, methanol, dsb) sebagai fluida kerjanya, bekerja berdasarkan prinsip peredaran termodinamika (motor udara panas), ditemukan pada tahun 1816 oleh Robert Stirling, KilmamockSkotlandia. Jadi pada Stirling Engine, gas hanya disusutkan dan kemudian dikembangkan dengan pemanasan dari luar [1].

Sebuah regenerator memungkinkan panas yang dihasilkan disimpan di dalam, sebagian menggantikan energi panas karena sedikitnya alih panas yang dimungkinkan melalui dinding heat-exchanger. Energi panas disimpan di dalam regenerator sementara gas penggerak menyusup ke ruangan yang dingin, dan kemudian dilepaskan sewaktu kembali ke ruangan ekspansi panas. Tenaga terjadi pada temperatur yang tinggi dan konstan, sangat ideal untuk setiap mesin. Kompresi terjadi pada temperatur rendah, dan hampir tidak ada energi panas yang hilang. Tenaga bersih yang dihasilkan 
adalah akibat perbedaan antara pengembangan gas bertemperatur tinggi dan mengkompresi gas bertemperatur rendah.

Mesin ini dapat membakar setiap bahan bakar padat (solid) atau cairan sebagai sumber pemanasannya. Hal ini menyebabkan Stirling Engine sangat menarik, khususnya pada situasi dimana bahan bakar konvensional saat ini sangat mahal dan sulit untuk memperolehnya. Beberapa jenis Stirling Engine, selain demikian efektif juga sangat mudah pembuatannya.

\section{Methanol}

Methanol atau spiritus adalah cairan bening dengan rumus kimia $\mathrm{CH} 3 \mathrm{OH}$ yang kadang-kadang disebut "alcohol kayu".Methanol adalah cairan bening dengan sifat polar, menjadikannya sebagai pelarut yang baik. Methanol juga sangat mudah terbakar, dan sangat beracun bagi manusia jika tertelan. Secara historis,methanol diciptakan ketika selulosa, gula utama dalam kayu dan beberapa tanaman lainnya, difermentasi oleh bakteri. Proses fermentasi ini menyebabkan zat yang mematikan untuk dikonsumsi, tetaoi berguna sebagai pelarut untuk tujuan ilmiah dan industri.

Methanol digunakan secara industry sebagai bahan anti beku, berbagai pelarut kimia, bahan bakar tertentu, pembuatan banyak plastic, dan dalam campuran alcohol yang ditujukan untuk penggunaan medis atau industry dan bukan dikonsumsi. lain : Adapun kegunaan methanol antara

1. Sebagai bahan untuk formaldehida. Bahan kimia ini dapat berasal dari methanol yang digunakan secara luas dalam produksi plastik, termasuk yang digunakan dalam bahan konstruksi, bagian mobil, cat, bahan peledak, dan kain buatan yang tahan kerut, juga sebagai bahan untuk mengawetkan mayat dalam spesimen laboratorium.

2. Sebagai bahan pelarut dari asam asetat, dimetil eter, dan propilena yang digunakan dalam anti-beku. Metanol sendiri juga bias menjadi anti-beku.

3. Bahan bakar karena sifat dan kegunaannya yang sangat mudah terbakar juga sebagi campuran bahan bakar lain untuk membantu dalam pembakaran bahan bakar lain tersebut.

Salah satu energi yang dibutuhkan manusia adalah energi listrik, namun ketersediaan energi ini tidak tercukupi dengan suplay bahan bakar pembangkit energi listrik yaitu bahan bakar fosil atau energi fosil.Ketersediaan bahan bakar fosil di dunia setiap tahun mengalami kenaikan, sehingga memaksakan kita untuk mencari bahan bakar atau energi alternatif pengganti bahan bakar fosil.Salah satu energi alternatifnya adalah pemanfatan senyawa kimia methanol (spiritus) listrik dengan teknologi yang bekerja dengan prinsip mengkonversi langsung energi panas menjadi energi listrik.Metanol merupakan senyawa alkohol dengan rumus kimia $\mathrm{CH}_{3} \mathrm{OH}$.Metanol merupakan bentuk alkohol paling sederhana.Pada keadaan atmosfer berbentuk cairan yang mudah menguap, tidak berwarna, mudah terbakar, dan beracun dengan bau yang khas (berbau lebih ringan dari etanol).Metanol digunakan sebagai bahan pendingin anti beku, pelarut, bahan bakar dan sebagai bahan additive bagi industri etanol[4].

\section{Joule Thief Inverter}

Sirkuit Joule thief dikenal sebagai rangkaian transistor pemblokiran sederhana yang bekerja sebagai pencuri energi yang bisa menghasilkan energi listrik besar dengan sumber energi sangat kecil.Rangkaian Joule-thief memiliki efisiensi tinggi, akselerasi handal dan respon dinamis yang sangat cepat.

Joule thief adalah rangkaian penaik tegangan (voltage booster) yang mampu berosilasi sendiri dengan komponen yang kecil, murah dan mudah dibuat, yang biasanya digunakan untuk menggerakkan beban yang ringan.Joule thief dapat menggunakan hampir seluruh energi dalam sebuah baterai sel-tunggal, bahkan yang memiliki tegangan jauh di bawah tegangan nominal sebuah baterai.Dinamakan joule thief, karena rangkaian ini "mencuri" energi (joule) dari sumber tegangan.

Rangkaian joule thief mengadopsi sistem discharge kapasitor elektrolit yang dipadukan dengan kapasitor nonpolar sebagai filter arus DC pada lilitan sekunder yang di seri dengan lilitan feedback. Hal ini akan menekan frekuensi kerja trafo ferrite transformator yang 
cenderung tinggi, sehingga arus output bisa lebih besar

\section{METODE}

Pembahasan mengenai pembangkit listrik hot air stirling engine dengan bahan bakar methanol menggunakan beban listrik bolak balik. Penelitian yang dilakukan dapat dijelaskan dengan lebih baik melalui blok diagram seperti yang terlihat pada Gambar berikut

\begin{tabular}{|c|c|c|}
\hline $\begin{array}{c}\text { Bahan } \\
\text { bakar } \\
\text { methanol(s } \\
\text { piritus) } \\
\text { yang telah } \\
\text { di isi pada } \\
\text { tabung } \\
\text { kaca mini. }\end{array}$ & $\begin{array}{c}\text { Energi panas } \\
\text { pembakaran } \\
\text { metanol } \\
\text { menggerakk } \\
\text { an } \\
\text { pembangkit } \\
\text { listrik hot air } \\
\text { stirling } \\
\text { engine dan } \\
\text { memutarkan } \\
\text { generator } \\
\text { Elektrik DC }\end{array}$ & $\begin{array}{c}\text { Hasil dari } \\
\text { Generator } \\
\text { tersebut akan } \\
\text { menghasilkan } \\
\text { Tegangan DC } \\
\text { yang kemudian } \\
\text { akan } \\
\text { dikonversikan } \\
\text { menjadi listrik } \\
\text { AC menggunakan } \\
\text { Inverter (Joule } \\
\text { Thief) dengan } \\
\text { beban Lampu } 3 \\
\text { Watt }\end{array}$ \\
\hline
\end{tabular}

Gambar 2. Blok Diagram Penelitian

Blok diagram diatas merupakan proses penelitian yang dilakukan setelah diimplementasikan. Berikut adalah keterangan dari setiap blok diagram pada gambar 1 .

1. Input

Pada blok input, pembakaran bahan bakar methanol sampai mencapai pada panas yang dibutuhkan.

2. Proses

Proses yang dilakukan adalah memanfaatkan energi panas bahan bakar metanol yang dibakar menjadi energi gerak, kemudian diubah menjadi energi listrik DC.

3. Output

Berdasarkan proses yang dilakukan, output akan menghasilkan tegangan DC yang akan dikonversikan menjadi tegangan $\mathrm{AC}$ dengan beban lampu 3 watt yang akan digunakan dalam analisa penelitian hot air stirling engine.

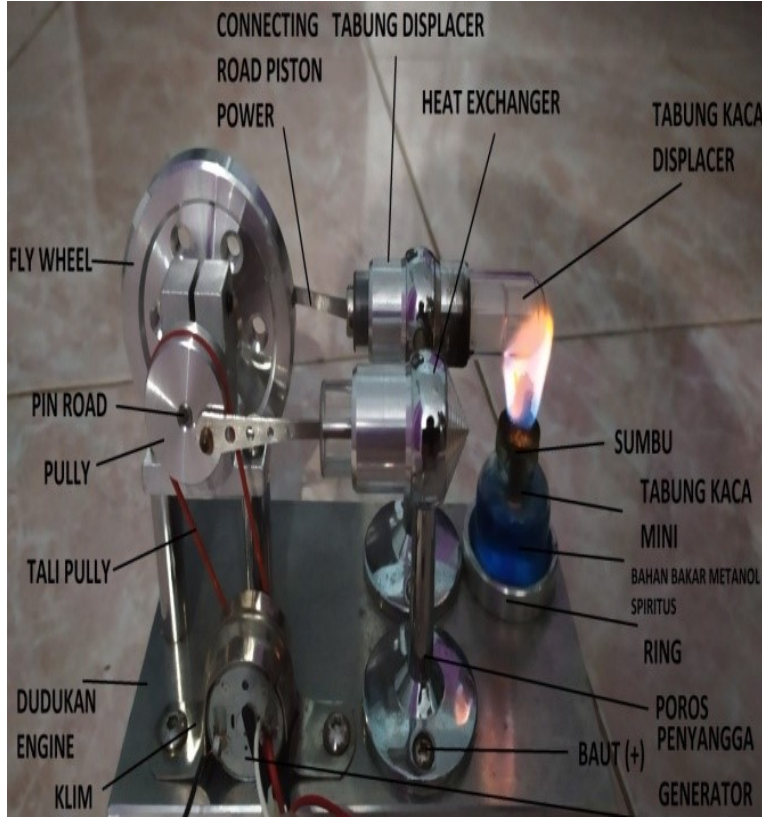

Gambar 3. Pembangkit Listrik Hot Air Stirling Engine Yang Sudah Menggunakan Bahan Bakar Methanol.

\section{Langkah kerja Penelitian}

Ada beberapa langkah kerja yang akan dilakukan guna memperoleh sebuah data yang sesuai dengan yang diinginkan penulis. Beberapa langkah tersebut diantaranya adalah:

1. Menyiapkan seluruh bahan-bahan dan peralatan penelitian.

2. Merakit joule thief inverter yang sesuai dengan karakteristik pembangkit listrik hot air stirlingdan menyesuaikan dengan beban listrik bolak balik.

3. Membersihkan alat penelitian dari kotorankotoran yang melekat agar bekerja lebih maksimal.

4. Setelah bersih, kemudian memasukkan bahan bakar methanol ke dalam tabung kaca mini.

5. Membakar sumbu tabung kaca mini dibawah tabung kaca displacer.

6. Menunggu hingga tabung kaca displacer panas dan sekaligus menghidupkan stopwatch agar dapat menghitung berapa lamapembakit listrik hot air stirling enginebekerja. 
7. Membantu fly wheel gerak mula dengan cara memutarkan fly wheel dengan jari tangan searah jarum jam hingga pembakit listrik hot air stirling enginebekerja yang diinginkan.

8. Jika pembakit listrik hot air stirling enginebekerja sudah sesuai yang diinginkan, kemudian mengukur temperature (T), kecepatan putaran fly wheel(RPM), waktu (s), arus (I), dan tegangan $(\mathrm{V})$ yang dihasilkan.

Jika sudah berhasil, mematikan sisa api ditabung pembakaran dan di sumbu tabung kaca mini.

\section{HASIL DAN PEMBAHASAN}

Pengujian bertujuan untuk menganalisis tegangan output, arus output, kecepatan putaran saat tanpa beban dan berbeban, dari pembangkit listrik hot air stirling engine dengan memanfaatkan bahan bakar methanol. Untuk melihat hasil dari pengujian, maka dapat dilihat pada tabel berikut.

Tabel 1. Hasil Output Pengujian Tanpa Beban

\begin{tabular}{cccccc}
\hline $\begin{array}{c}\text { Waktu } \\
\text { (detik) }\end{array}$ & $\begin{array}{c}\text { Tempe } \\
\text { ratur } \\
\text { dingin } \\
\left({ }^{\circ} \mathbf{C}\right)\end{array}$ & $\begin{array}{c}\text { Temper } \\
\text { atur } \\
\text { panas } \\
\left({ }^{\mathbf{0}} \mathbf{C}\right)\end{array}$ & $\begin{array}{c}\text { Kecepata } \\
\text { n putaran } \\
(\mathbf{r p m})\end{array}$ & $\begin{array}{c}\text { Tegan } \\
\text { gan } \\
(\mathbf{V})\end{array}$ & $\begin{array}{c}\text { Aru } \\
\mathbf{s} \\
(\mathbf{I})\end{array}$ \\
\hline 0 & 0 & 0 & 0 & 0 & 0 \\
5 & 23 & 38 & 200 & 4.8 & 0.5 \\
10 & 25 & 51 & 359 & 4.8 & 0.4 \\
15 & 32 & 64 & 402 & 4.9 & 0.4 \\
20 & 37 & 72 & 491 & 5.0 & 0.5 \\
& & & & & \\
\hline
\end{tabular}

Pembangkit listrik hot air stirling engine dengan menggunakan bahan bakar methanol saat tanpa beban pada suhu pada waktu 20 detik dengan suhu dingin $37^{\circ}$ dan suhu panas $37^{\circ}$, telah menghasilkan tegangan 5 volt, arus $0.5 \mathrm{~A}$ dan kecepatan putaran yang dihasilkan $491 \mathrm{rpm}$
Tabel 2. Hasil Output Pengujian Dengan Beban

\begin{tabular}{cccccc}
\hline $\begin{array}{c}\text { Wakt } \\
\mathbf{u} \\
(\mathbf{d e t i} \\
\mathbf{k})\end{array}$ & $\begin{array}{c}\text { Temperat } \\
\mathbf{u r} \\
\mathbf{d i n g i n} \\
\left({ }^{\circ} \mathbf{C}\right)\end{array}$ & $\begin{array}{c}\text { Temperat } \\
\text { ur panas } \\
\left({ }^{\circ} \mathbf{C}\right)\end{array}$ & $\begin{array}{c}\text { Kecepat } \\
\text { an } \\
\text { putaran } \\
(\mathbf{r p m})\end{array}$ & $\begin{array}{c}\text { Tegang } \\
\text { an } \\
(\mathbf{V})\end{array}$ & $\begin{array}{c}\text { Aru } \\
\mathbf{s} \\
(\mathbf{I})\end{array}$ \\
\hline 0 & 0 & 0 & 0 & 0 & 0 \\
5 & 23 & 37 & 133 & 5.1 & 1.5 \\
10 & 25 & 53 & 142 & 5.2 & 1.4 \\
15 & 32 & 67 & 301 & 5.8 & 1.5 \\
20 & 37 & 73 & 334 & 6.0 & 1.4 \\
\hline
\end{tabular}

Hasil pengukuran keluaran arus dan tegangan dengan beban lampu 3 watt pada pembangkit listrik hot air stirling engine . pada waktu 20 detik dengan suhu dingin $37^{\circ} \mathrm{C}$ dan suhu panas $72^{\circ} \mathrm{Cdan}$ kecepatan putaran roda stirling $334 \mathrm{rpm}$ adalah $6.0 \mathrm{~V}$ dan arus $1.4 \mathrm{~A}$.

\section{KESIMPULAN}

Berdasarkan hasil penelitian dapat disimpulkan bahwa saat berbeban kecepatan putaran yang dihasilkan jauh lebih kecil dimana pada saat tanpa beban pada waktu 20 detik putaran yang dihasilkan $491 \mathrm{rpm}$, sedangkan saat berbeban kecepatan putaran yang dihasilkan $334 \mathrm{rpm}$. Besarnya tegangan yang terukur pada waktu 20 detik saat tanpa beban sebesar 5.0 volt, sedangkan saat berbeban tegangan yang dihasilkan 6.0 volt. Arus yang terukur saat tanpa beban sebesar $0.5 \mathrm{~A}$, dan saat berbeban $1.4 \mathrm{~A}$, pada waktu 20 detik

\section{DAFTAR PUSTAKA}

[1] S. Narayan and V. Gupta, "Overview Of Working Of Striling Engines,” vol. 21, no. 4, pp. 45-53, 2015.

[2] Al-Fikri. Harry Iqbal, "Analisis Pembangkit Listrik Dengan Generator Stirling," vol. 91, pp. 399-404, 2017.

[3] K. Eksperimental and M. Stirling, "Kaji Eksperimental Mesin Stirling Tipe B Menggunakan Variasi Bahan Bakar Biomassa," vol. 5, pp. 47-57, 2013. 
[4] Evalina E, Khairil M, Rimbawaty,’Pemanfaatan Bahan Bakar Sampah Plastik Dengan Menggunakan Hot Air Stirling Engine", Semnastek UISU 2019 pp. 71-75
[5] Syafriyudin, "Pembangkit Listrik Tenaga Panas Matahari Berbasis Mesin Stirling Engine." pp. 187-192, 2013. 